\title{
Improved extension practices for sheep and beef farmers
}

\author{
D.I. GRAY ${ }^{1}$, A.M. SEWELL ${ }^{2}$, M. HARTNETT ${ }^{2}$, B.A. WOOD ${ }^{1}$, \\ P.D. KEMP ${ }^{1}$, H.T. BLAIR ${ }^{3}$, P.R. KENYON ${ }^{3}$ and S.T. MORRIS ${ }^{3}$ \\ ${ }^{1}$ Institute of Agriculture and Environment, College of Sciences, Massey University, New Zealand \\ ${ }^{2}$ Institute of Education, College of Humanities and Social Sciences, Massey University, New Zealand \\ ${ }^{3}$ Institute of Veterinary, Animal and Biomedical Sciences, College of Sciences, Massey University, New Zealand
} d.i.gray@massey.ac.nz

\begin{abstract}
Innovation is critical for maintaining New Zealand's competitive advantage in agriculture and central to this is farmer learning and practice change. Despite the importance of farmer learning, limited research has been undertaken in New Zealand. In this study, an extension programme was developed based upon educational theory and research and then evaluated over a 3 years to identify the factors that were important for farmer learning and practice change. This paper provides a brief overview of findings of a 3 year interdisciplinary study conducted at Massey University with 23 farmers that investigated the critical factors that support farmers' learning. The five critical success factors and the seven educational principles identified from this study provide guidelines for how science should interact with farmers to foster effective innovation. These findings are also applicable to other extension approaches such discussion groups, monitor farms and sustainable farming fund initiatives where farmers work with scientists and/or rural professionals.
\end{abstract}

Keywords: farmer learning, extension, practice change, herb pastures, innovation, community of practice

\section{Key messages}

- To foster an effective learning community, facilitators need to build relationships based on trust and mutual respect, provide time and space for dialogue and ensure power is shared by the actors

- Reinforcement both over time and through different learning activities is important for learning

- Extension activities need to help farmers to become evidence-based inquirers into their own practice.

\section{Introduction}

A vibrant, productive and wealthy farming sector is important not only for the standard of living of all New Zealanders, but also for ensuring vibrant rural communities and investment in a more environmentally friendly agriculture. Innovation is critical for maintaining New Zealand's competitive advantage in agriculture and recent research by Turner et al. (2013) has investigated how this can be enhanced. Central to such innovation is farmer learning because the ability to identify, assimilate and exploit knowledge from the environment is critical for a firm's competitive advantage (Cohan \& Levinthal 1989). Extension plays an important role in helping farmers learn about both their existing and new practices (Sherson et al. 2002). Learning can result in an improved or new understanding of relevant concepts and this in turn can lead to the dis-adoption of existing practices, improved implementation of existing practices and/or the adoption of new practices that maintain New Zealand's competitive advantage (Gray et al. 2003). However, Leeuwis \& Aarts (2011) argue that much of what happens in the name of extension often fails to provide the conditions necessary for learning and practice change. Education theory may provide insights into farmer learning that can be used to enhance extension practice and to this end, educationalists have been incorporated into the research team for this study.

Recent thinking on extension has highlighted the value of industry partnerships with universities so that farmers can interact directly with scientists (Llewellyn 2007; Hunt et al. 2012). Central to this approach is the value of knowledge exchange and the collaborative partnerships between farmers and scientists that focus on evidence-based extension and co-innovation (e.g. Röling 2009; Franz et al. 2010; Eastwood et al. 2012). Such partnerships create a space for dialogue between farmers and scientists to share and challenge ideas, to co-construct new ideas, and to negotiate new actions (Llewellyn 2007; Leeuwis \& Aarts 2011). In this paper, an extension of the work reported in Sewell et al. (2014), the adoption of a partnership approach shifts the focus of the science away from publishing papers to the end game: farmer learning, innovation and the creation of a diversity of ideas, that lead ultimately to effective practice change within different farming contexts. Based on a 3-year project where scientists worked with farmers, the paper describes the critical success factors and principles that scientists and also extension agents, could use to enhance farmer learning and practice change.

\section{Methods}

A 3-year study was conducted where farmers worked with an interdisciplinary team of three animal scientists, one agronomist and four social scientists, including two 
educationalists, in a sequence of learning experiences designed around a lamb finishing trial at Massey University (see Sewell et al. (2014) for a more detailed description of the method). The experiment was part of a research project comparing two herb (plantain and plantain and chicory) and legume pastures with a perennial ryegrass and white clover pasture. Previous research (Kemp et al. 2010) with multiple-bearing ewes had suggested that herb pastures could provide an advantage over perennial ryegrass white clover pastures in relation to lamb finishing.

Farmers were selected from individuals known to the science team. Purposive sampling (Patton 1990) was used to identify 23 farmers located within 2 hours of the university for logistical reasons. A diverse group of farmers was selected in relation to farming experience (15 - 45 years), geographic location (Manawatu, Hawkes Bay, Wairarapa), farming systems and use (or non-use) of herb pastures. An important criterion used in their selection was that they were open to change. The 23 selected farmers were all male and ranged in age from their late 20 's to early 60 's. They represented 18 farms because some were represented by two family members. Four farmers were managers and the rest were owner operators. The natural scientists' role was to run the trial, and provide results that formed the basis for discussion and debate. The social scientists investigated the workshop process to determine how it influenced farmer learning and practice change. The two science groups jointly planned the learning experiences, but were informed by education and extension theory.

The farmers attended four workshops/year that were primarily centred on the trial, but also involved farm visits and other activities. The core feature of these learning experiences was observation and discussion of trial data. Associated with this were a wide variety of experiences designed to promote learning about herb pasture establishment, management and performance. Social activities were planned to support the development of relationships. Other activities were designed simply to appeal to the farmers' wider interests (e.g. sheep autopsy, precision agriculture).

At the end of each workshop, an audio-recorded focus group discussion was conducted with six randomly selected farmers to find out the ways in which the activities had supported or detracted from their learning and the learning activities they would like at the next workshop. This action learning approach (Kolb 1984) was pivotal in providing feedback and useful insights that informed subsequent workshops. Audio-recorded semi-structured interviews were conducted with the farmers at the end of the 3-years to find out what had influenced their learning and practice change. Participant observation, using field notes, photographs and video, was also used to collect data throughout the workshops.
The audio-recorded material was transcribed and then analysed using qualitative data analysis approach (Yin 2003). Findings were triangulated with the field data.

\section{Results}

The study identified five critical success factors and seven principles of learning that scientists need to consider when working with a group of farmers to bring about practice change. Of the five critical success factors, the most important was the development of a learning community. Ensuring farmer interest, making connections to their farming systems, ensuring alignment between the learning activities and the science behind the new technology, and supporting evidence-based farmer inquiry into their current practices were also important for fostering learning and practice change. From these five critical success factors, seven principles of learning emerged (Figure 1) that have also been shown to be important in education theory (Aitken \& Sinnema 2008).

\section{A farmer-scientist learning community}

A critical success factor was the development of an inclusive "community of practice" by the science team where farmers and scientist jointly "engaged" in learning. Making explicit to farmers that they were involved in a learning group and reinforcing this concept during the workshops was important. As a result, farmers came to the workshops "expecting to learn". Central to the creation of this "open" learning forum was the development of mutually respectful and trusting relationships (Figure 1). The farmers respected the scientists' wealth of evidence-based knowledge about herb pastures and their understanding of farming systems. Trust and mutual respect were further fostered by the willingness of the scientists to share both positive and negative experimental outcomes and take note of the farmers' suggestions. The farmers reported that they often learnt more when the scientists shared some aspect about the trial that had gone wrong. Trust and mutual respect were also built because the scientists provided objective information that was unbiased by commercial considerations, a problem farmers often identified with information provided by commercial firms. Trust and mutual respect were also built because the scientists actively listened to the farmers and valued their knowledge and experience.

Providing the opportunity for informal dialogue was important in fostering a learning community. Farmers preferred to discuss issues in small groups that normally comprised three to six people. Space was created by the science team for informal dialogue by providing time within the workshop schedule. This was critical for learning, but it is something not often valued in a science system dominated by milestones 


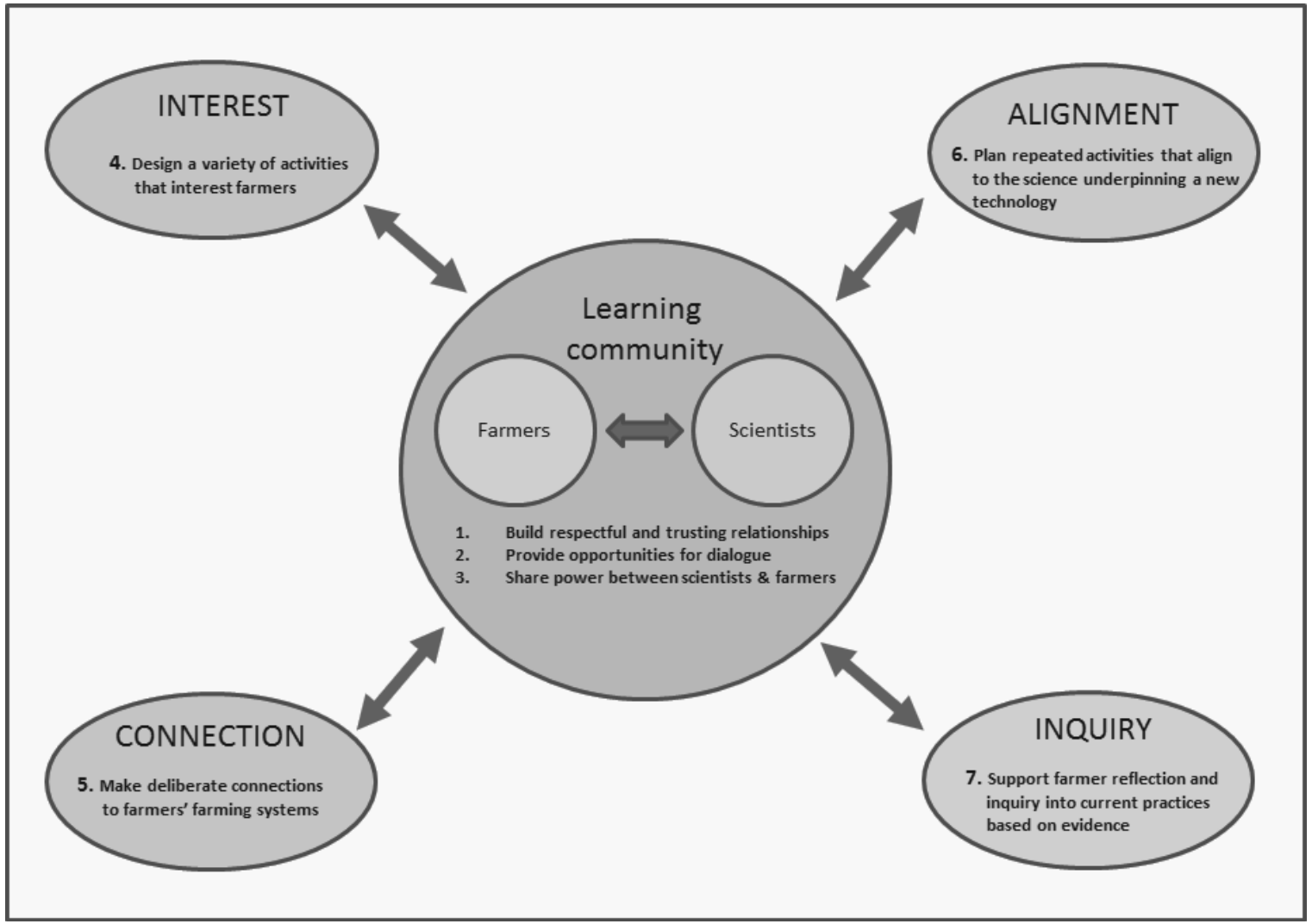

Figure 1

Critical success factors and educational principles that promote farmer learning and practice change.

and outputs. The research team used the term "slow science" to describe this way of interacting. During these interactions, farmers tested ideas with other farmers and the scientists, were exposed to new ideas, and as one farmer stated, the workshop became " $a$ place to hatch new ideas". As trust and mutual respect developed, the farmers' confidence or self-efficacy increased. This led to much greater, more equal and deeper interactions between the participants. An important element to emerge from this study was the importance of enhancing farmers' self-efficacy to bring about practice change and this is the focus of a future study. Self-efficacy is a farmers judgment of their capability to undertake a specific action or practice (Wilson et al. 2015).

The third feature of the community of practice was the importance of the science team "sharing power" with the farmers (Figure 1). Unlike a normal topdown approach, power did not reside solely with the scientists because of their scientific expertise. The experience and practical expertise of the farmers was highly regarded by the scientists and often drawn on in discussions during the workshop. The scientists shared their decision-making processes in relation to the management of the trial with the farmers and sought suggested improvements. They also sought input from the farmers about ideas for learning experiences at subsequent workshops and areas for future research. Gradually, this power-sharing culture, in combination with the trust and mutual respect that had developed, helped both parties become more open and this allowed for a more critical, but constructive dialogue between them that was important for on-going inquiry.

\section{Learning experiences that interest, connect, and align to science}

The science team developed learning experiences that created interest in the farmers and this was central to their learning (Figure 1). Allowing the farmers to observe the trial as well as providing trial data were valuable because farmers could visualise what the data looked like, which to them was much more valuable than just being given tabulated data. Similarly, the scientists provided the farmers with learning experiences related to key aspects of herb pastures such as: grazing management, establishment, herbicide management, meat quality and stock performance. Such topics were highly relevant to the farmers and created interest in the group. One farmer commented that his main reason for attending the group was for "mental stimulation". Other activities outside of herb pastures were also used to foster interest. This included: 
a sheep autopsy, lucerne management and condition scoring sheep. Because of the geographic dispersal and diversity of farmers, one of the focus group sessions highlighted that they were interested in how different members of the group farmed and used herb pastures. To meet this interest, an afternoon was arranged where the farmers met in small groups and discussed their farming systems. Leading on from this, farm visits to several of the more progressive farmers were organised to provide useful learning experiences.

The learning experiences were deliberately designed by the science team so that the farmers could see the relevance of, and make connections to, their own diverse farming systems (Figure 1). Data were provided so that farmers could compare their stock performance to that of the trial. Similarly, chicory taproots were exhumed to help the farmers understand the importance of root reserves and spelling chicory in the autumn. The majority of learning activities at the workshops were designed to align directly to the important principles associated with herb pasture management (Figure 1). Reinforcement of these important principles by the science team at 3-monthly intervals through a range of different learning experiences was important for the farmers' learning. Several of the farmers commented that it was not until they had seen these principles in action under different seasonal conditions and/or reinforced through different learning activities that they began to understand the complexity of managing herb pastures.

\section{Developing a disposition for inquiry}

In the early workshops, the farmers did not feel qualified to challenge the scientists about their research or provide ideas for further investigation. However, as trust and mutual respect developed, the farmers began to participate with the scientists in their inquiry processes (Figure 1). During the programme, they became increasingly confident to question the scientists' decisions, interrogate the data with the scientists, posit ideas for future research and share their experiencebased knowledge based of herb pastures. Knowing they could contribute ideas and that the scientists were receptive to such input further motivated the farmers to be involved in the programme. As such, the inclusive culture the science team had created fostered inquiry processes. During the programme, it became increasingly evident that the farmers were involved in reflective thinking, both at the workshop and back on their farms. Much of this reflective inquiry was about how to adapt this new knowledge about herb pastures to their own unique farming systems. Ultimately, this reflective inquiry led to a plethora of practice change onfarm where the principles of herb pasture management were adapted to each farmer's unique context.

\section{Learning leading to practice change}

Improving farmer learning about herb pastures is of limited value unless it brings about practice change and improved outcomes for farmers. Over the 3 years, 39\% of the farmers increased their area in herb pastures, $61 \%$ of the farmers changed their management practices and $33 \%$ of farmers changed how they used their herb pastures. Importantly, practice change appeared to be accelerating because when the farmers were asked about changes they planned to make over the next 1 - 2 years, $72 \%$ of farmers expected to increase their area in herb pasture including four farmers who had not previously grown it. Some 33\% of farmers planned a change in terms of how they used their herb pastures in relation to sheep and $28 \%$ of the farmers planned a change in relation to cattle.

Also of interest was the degree of innovation that occurred on several farms over time. Initially, farmers often considered herb pastures as a substitute for annual summer forage crops. However, as they learnt more about herb pastures, much more complex changes were introduced to their farming systems. One farmer moved from a single paddock of plantain to putting almost half his farm into herb pastures, introducing irrigation, using the forage for multiple-bearing ewes, lamb and bull finishing and moving from a breeding flock to buying in replacements and using terminal sires. Another farmer established over 100 ha of chicory for lambing by multiple-bearing ewes, and then post-weaning he used it for lamb trading. The chicory was also used improve ewe hogget lambing percentage such that the farmer could breed all his replacements from these, and this then allowed him to put a terminal sire over his entire ewe flock and capture hybrid vigour.

\section{Discussion}

Drawing on the educational literature (Aitken \& Sinnema 2008), five critical success factors were identified that scientists should use to foster farmer learning and practice change: community, connection, interest, alignment and inquiry. Supporting these five factors are seven educational principles that are central to learning. Education has long recognized the importance of learning communities in relation to capacity building (Lieberman 2000; Stoll et al. 2006). Similarly, the shift in extension from a topdown to a collaborative and participatory approach has recognized the importance of social learning and creating effective learning communities (Llewellyn 2009; Röling 2009; Franz et al. 2010; Lyon et al. 2010; Leeuwis \& Aarts 2011). However, to foster an effective learning community, facilitators need to build relationships based on trust and mutual respect. In education, it is well known that building high levels 
of mutual support and trust promotes learning (Bryk \& Schneider 2003). Similar findings have been reported in relation to farmer learning (e.g. Sherson et al. 2002; Lyon et al. 2010; Fisher 2013).

Providing opportunity for dialogue, the second principle, was important for learning because it allowed the exchange of ideas. However, such an approach requires time, hence the term "slow science" coined by the research team. During such dialogue, the misconceptions by both farmers and scientists can be rectified, new ideas can be "hatched" and new knowledge co-constructed or tailored to specific farming contexts. The importance of the dialogic approach has long been understood in education (e.g. Wells 2000; Mercer \& Alexander 2008) and is central to, but not often formally recognized, in discussion groups (Sherson et al. 2002).

Mutual power sharing was the third principle of community. This was important because it allowed farmers to play an active role with the science team in setting both the workshop and future research agendas. Power sharing created a more open environment where the expertise and knowledge of both farmers and scientists were valued which in turn fostered the co-construction of new knowledge. The importance of power sharing has been long recognized in the education research (Paavlova et al. 2004) and it is now being identified in extension research (e.g. Lyon et al. 2010).

The creation of interest is the fourth educational principle where learning activities are designed to capture the farmer's interest and, as a result, motivate them to learn (Brophy 2010; Aitken \& Sinnema 2008). Linked to this is the fifth principle where the aim is to make connections between the topic of the learning activity and the learner's own context (Aitken \& Sinnema 2008). Nuthall (2007) argued that farmers are more likely to learn from activities that are relevant to their needs and connect to their experiences. Designing recurrent learning activities that align with the science underpinning a new technology, the sixth educational principle is critical for fostering learning (Aitken \& Sinnema 2008). The use of repeated learning activities, both over time and through using different approaches, reinforces learning and enhances farmers' ability to embed the new ideas in their long-term memories (Nuthall, 2007).

The seventh principle, inquiry (Aitken \& Sinnema 2008), is about supporting farmers to reflect on their own practice, to consider the role new technologies might play in this, to reflect on new practices once implemented and to base such reflections on evidence. Sinnema \& Aitken (2008) argued that practitioner inquiry is fundamental when selecting and applying new research findings in a new context. Scientists helped the farmers and provided useful resources for their inquiry process, but such inquiry could be fostered without input from scientists. For example, Sherson et al. (2002) in a study of an expert discussion group facilitator identified that one of his key aims was to help farmers reflect on both new and existing practices to foster learning and practice change. It is this capability, not information that is central to an innovative primary sector. As such, extension activities need to help farmers to become evidence-based inquirers into their own practice.

\section{Conclusions}

The project demonstrated the power of bringing together farmers, agricultural scientists and social scientists and incorporating educational theory to better understand how to enhance farmer learning and practice change. Central to this has been the on-going development of an inclusive professional community of learners. Fostering farmer interest, making connections to their farming systems, ensuring alignment between the learning activities and the science behind the new technology, and supporting farmer inquiry into their current practices that is based on evidence have been critical for learning and practice change. The five critical success factors and the seven educational principles provide guidelines for how science should interact with farmers to foster effective innovation.

The research has identified the critical success factors and principles that are important for extension planning. This case study was of a university-based scientist farmer community of practice that had a specific focus on improving practice in relation to herb pasture use. However, the five critical success factors and the seven principles of learning are equally applicable to other extension approaches such discussion groups, monitor and demonstration farms and Sustainable Farming Fund initiatives where farmers work with scientists and/or rural professionals. A key issue will be to determine how these different approaches are best managed to implement these critical success factors and learning principles.

\section{ACKNOWLEDGEMENTS}

The authors would like to thank the farmers for their generous input into the project. Dr Somasiri and Dr Cranston shared their doctoral experiments and Mark Osborne provided technical assistance. Funding was provided through the Massey University Team Research Medal Award for the International Sheep Research Group, and from the National Research Centre for Growth and Development, C. Alma Baker Trust and PGG Wrightson Seeds. 


\section{REFERENCES}

Aitken, G.; Sinnema, C. 2008. Effective pedagogy in social sciences/tikanga ā iwi: Best evidence synthesis iteration (BES), Wellington, N.Z., Ministry of Education.

Bryk, A.S.; Schneider, B. 2003. Trust in schools: A core resource for school reform. Educational Leadership 60: 40-45.

Cohen, W.M.; Levinthal, D. 1989. Innovation and learning: The two faces of $\mathrm{R} \& \mathrm{D}$. The Economic Journal 99: 569-596.

Eastwood, C.R.; Chapman, D.F.; Paine, M.S. 2012. Networks of practice for co-construction of agricultural decision support systems: Case studies of precision dairy farms in Australia. Agricultural Systems 108: 10-18.

Fisher, R. 2013. 'A gentleman's handshake': The role of social capital and trust in transforming information into useable knowledge. Journal of Rural Studies 31: 13-22.

Franz, N.; Piercy, F.; Donaldson, J.; Richard, R.; Westbrook, J. 2010. How farmers learn: Implications for agricultural educators. Journal of Rural Sciences 25: 37-59.

Gray, D. I.; Parker, W. M.; Kemp, E. A. 2003. Achieving $4 \%$ productivity: Implications from a longitudinal study of farmer learning in dairy farming. Proceedings of the New Zealand Society of Animal Production 63: 116-119.

Hunt, W.; Birch, C.; Coutts, J.; Vanclay, F. 2012. The many turnings of agricultural extension in Australia. The Journal of Agricultural Education and Extension 18: 9-26.

Kemp, P.D.; Kenyon, P.R.; Morris, S.T. 2010. The use of legume and herb forage species to create high performance pastures for sheep and cattle grazing systems. Revista Brasileira de Zootecnia 39: 169174.

Leeuwis, C.; Aarts, N. 2011. Rethinking communication in innovation processes: Creating space for change in complex systems. The Journal of Agricultural Education and Extension 17: 21-36.

Lieberman, A. 2000. Networks as learning communities: Shaping the future of teacher development. Journal of Teacher Education 51: 221227.

Llewellyn, R.S. 2007. Information quality and effectiveness for more rapid adoption decisions by farmers. Field Crops Research 104: 148-156.
Lyon, A.; Bell, M.; Croll, N.S.; Jackson, R.; Gratton, C. 2010. Maculate conceptions: Power, process, and creativity in participatory research. Rural Sociology 75: $538-559$.

Mercer, N.; Littleton, K. 2007. Dialogue and the development of children's thinking: A sociocultural approach. London, Routledge.

Nuthall, G. 2007. The hidden lives of learners. Wellington, NZCER.

Paavola, S.; Lipponen, L.; Hakkarainen, K. 2004. Models of innovative knowledge communities and three metaphors of learning. Review of Educational Research 74: 557-576.

Röling, N. 2009. Pathways for impact: Scientists' different perspectives on agricultural innovation. International Journal of Agricultural Sustainability 7: 83-94.

Sewell, A. M.; Gray, D. I.; Blair, H. T.; Kemp, P. D.; Kenyon, P. R.; Morris, S. T.; Wood B. A. 2014. Hatching new ideas about herb pastures: Learning together in a community of New Zealand farmers and agricultural scientists. Agricultural Systems 125: 63-73.

Sherson, D.; Gray, D. I.; Reid, J. I.; Gardner, J. 2002. The facilitation of learning groups: A study of a dairy discussion group facilitator. In: Proceedings of the International Farm Management Congress, Wageningen, The Netherlands.

Stoll, L.; Bolam, R.; McMahon, A.; Wallace, M.; Thomas, S. 2006. Professional learning communities: A review of the literature. Journal of Educational Change 7: 221-258.

Turner, J. A.; Rijswijk, K.; Williams, T.; Barnard, T.; Klerkx, L. 2014. Challenges to effective interaction in the New Zealand agricultural research and extension system: An innovation systems analysis. Extension Farming Systems Journal 9: 89-98.

Wells, G. 2000. Dialogic inquiry in education: Building on the legacy of Vygotsky. In: Lee, C.; Smagorinsky, P. (Eds.), Cambridge, London. Vygotskian perspectives on literacy research. pp. 51-85.

Wilson, L; Rhodes, A. P.; Dodunski, G. 2015. Parasite management extension - challenging traditional practice through adoption of a systems approach. New Zealand Veterinary Journal 63: 292-300.

Yin, R. 2003. Case study research: design and methods. Thousand Oaks, CA, Sage Publications. 